\title{
Monitoring and interpreting the ocean uptake of atmospheric $\mathrm{CO}_{2}$
}

\author{
By Andrew J. Watson ${ }^{1, *}$, Nicolas Metzl ${ }^{2}$ And Ute Schuster ${ }^{1}$ \\ ${ }^{1}$ School of Environmental Sciences, University of East Anglia, \\ Norwich NR4 7 TJ, UK \\ ${ }^{2}$ LOCEAN, Institut Pierre Simon Laplace, CNRS, Université Pierre et \\ Marie Curie, 4 Place Jussieu, 75252 Paris Cedex 05, France
}

The oceans are an important sink for anthropogenically produced $\mathrm{CO}_{2}$, and on time scales longer than a century they will be the main repository for the $\mathrm{CO}_{2}$ that humans are emitting. Our knowledge of how ocean uptake varies (regionally and temporally) and the processes that control it is currently observation-limited. Traditionally, and based on sparse observations and models at coarse resolution, ocean uptake has been thought to be relatively invariant. However, in the few places where we have enough observations to define the uptake over periods of many years or decades, it has been found to change substantially at basin scales, responding to indices of climate variability. We illustrate this for three well-studied regions: the equatorial Pacific, the Indian Ocean sector of the Southern Ocean, and the North Atlantic. A lesson to take from this is that ocean uptake is sensitive to climate (regionally, but presumably also globally). This reinforces the expectation that, as global climate changes in the future owing to human influences, ocean uptake of $\mathrm{CO}_{2}$ will respond. To evaluate and give early warning of such carbonclimate feedbacks, it is important to track trends in both ocean and land sinks for $\mathrm{CO}_{2}$. Recent coordinated observational programmes have shown that, by organization of an observing network, the atmosphere-ocean flux of $\mathrm{CO}_{2}$ can, in principle, be accurately tracked at seasonal or better resolution, over at least the Northern Hemisphere oceans. This would provide a valuable constraint on both the ocean and (by difference) land vegetation sinks for atmospheric $\mathrm{CO}_{2}$.

Keywords: $\mathrm{CO}_{2}$; carbon cycle; greenhouse gases; atmospheric oxygen

\section{The global ocean sink for $\mathrm{CO}_{2}$}

Historically, the first estimates of the size of the global ocean sink for humanderived $\mathrm{CO}_{2}$ began to be made in the early 1960s, shortly after the first accurate measurements of the rate of rise of $\mathrm{CO}_{2}$ in the atmosphere were begun by C. D. Keeling. Work by Bolin \& Eriksson [1] gave a clear description of the uptake process [2]. These studies indicated that the earlier belief that the oceans would rapidly absorb $\mathrm{CO}_{2}$ so quickly that it could not accumulate in the atmosphere were incorrect, and predicted that, by 2000, atmospheric $\mathrm{CO}_{2}$ *Author for correspondence (a.watson@uea.ac.uk).

One contribution of 17 to a Discussion Meeting Issue 'Greenhouse gases in the Earth system: setting the agenda to 2030 '. 
might have increased by 40 per cent over the pre-industrial concentrations. Later modelling efforts [3,4] were 'box model' descriptions calibrated using the observed distribution of ${ }^{14} \mathrm{C}$ in the oceans, as measured by the Geochemical Ocean Sections (GEOSECS) campaigns of the early 1970s. At that period, it was not known whether the terrestrial biosphere was taking up $\mathrm{CO}_{2}$ or was at a steady state: it seemed possible that the anthropogenic carbon budget was a simple balance between fossil-fuel emission, ocean uptake and accumulation in the atmosphere. However, by the early 1990s, it became clear that there was both a substantial terrestrial source from deforestation, and a 'missing sink', which was identified as net uptake by the land vegetation.

Since then, attempts to separate the ocean and land uptakes have proliferated, mostly by methods that attempt to define the ocean sink. The Intergovernmental Panel on Climate Change (IPCC) Fourth Assessment Report (AR4) lists seven quasi-independent methods of deriving the annual global ocean $\mathrm{CO}_{2}$ uptake. Some of these are strongly model-based, using biogeochemical ocean carbon models (e.g. $[5,6])$. Others combine models and observations, such as calculations of ocean 'anthropogenic' carbon using observations of oxygen, nutrients and carbon in the ocean $[7,8]$ and inversion modelling of ocean or atmosphere $[9,10]$. Finally, some are mostly observation-based with little reliance on complex models, such as the estimates based on atmospheric $\mathrm{O}_{2} / \mathrm{N}_{2}$ ratios and $\mathrm{CO}_{2}$ [11] and those derived by integrating observations of sea-surface $p \mathrm{CO}_{2}$ over the entire surface of the global ocean [12]. All these methods derive subtly different quantities. Without reviewing them exhaustively, we note here the most important differences between them. Some yield the total flux across the surface ocean, while others give only a part of it, and it is important to understand why is this so. The actual net air-sea flux is usually expressed as the sum of that due to natural processes, which can be either a net ingassing or outgassing, and a flux forced by rising atmospheric $\mathrm{CO}_{2}$, labelled 'anthropogenic' and always directed into the ocean. However, this decomposition is only strictly valid if the ocean circulation has been in steady state since pre-industrial times: if it has not been, it is more difficult to say exactly what the anthropogenic component refers to. Of course, in detail, the ocean is never in a steady state, and even if it had been from pre-industrial times up to now, we would not expect it to remain so under future climate change. The 'natural' part of the $\mathrm{CO}_{2}$ flux can therefore be further broken down into a pre-industrial component, itself subject to natural oscillations and variability with time, and changes since the industrial revolution due to the secondary effects of rising $\mathrm{CO}_{2}$ on climate, ocean circulation and biogeochemistry: we might term these last effects 'indirect anthropogenic'.

Attempts to assess the ocean sink for $\mathrm{CO}_{2}$ using sea-surface $p \mathrm{CO}_{2}$, observations, inversions of $\mathrm{CO}_{2}$ in the atmosphere or total carbon in the ocean, all calculate the total atmosphere-ocean flux, i.e. the sum of preindustrial, direct and indirect anthropogenic components. While for individual basin-wide areas the net flux can be in either direction, integrated over the entire surface of the global ocean it is thought that pre-industrially the oceans were a net source to the atmosphere of $0.4-0.7 \mathrm{Pg} \mathrm{Cyr}^{-1}$ [13]. This is the socalled 'riverine flux', which before the Industrial Revolution ran in a circuit from oceans to atmosphere, from there to land vegetation, from soils into rivers and thence back to the ocean, so that overall each component was 
closely in balance. Because of this pre-industrial outgassing by the ocean, the global 'anthropogenic' flux (direct plus indirect) into the oceans is this much greater today than the total flux actually measurable [12]. In contrast to the direct measurement techniques, in model assessments, the anthropogenic uptake can be unambiguously defined, and most model studies report the anthropogenic flux as the amount by which ocean uptake has increased since the Industrial Revolution, which is the quantity most usually needed in anthropogenic carbon budgets (e.g. [14]). The widely used atmospheric oxygen technique for quantifying land and ocean sinks divides total land-plus-ocean $\mathrm{CO}_{2}$ uptake into a component that is accompanied by a stoichiometric oxygen release, assumed to be due to land vegetation, with the residual assumed to be due to oceanic uptake. A correction is necessary for the outgassing of oxygen because of the warming of the ocean [11]. Although we can make a good estimate of this warming correction, a further adjustment would be needed if the size of the approximately $700 \mathrm{PgC}$ reservoir of dissolved organic carbon in the ocean is changing systematically. Because observations of organic carbon in the ocean are much more sparse and less accurate than those of the inorganic carbon, there is currently no way to address this issue. While the ocean flux derived from the oxygen technique is not precisely equivalent to either the 'anthropogenic' or the 'actual' ocean-atmosphere flux, it is closer to the anthropogenic flux derived by models. All the methods give values consistent with the net anthropogenic flux being about $2.2 \mathrm{Pg} \mathrm{Cyr}^{-1}$ during the $1990 \mathrm{~s}$, with uncertainty estimates of approximately $0.6 \mathrm{Pg} \mathrm{C}_{\mathrm{Cr}}{ }^{-1}$.

\section{Is the sink increasing or decreasing?}

The expectation is that the ocean sink for $\mathrm{CO}_{2}$ has been increasing in recent decades. All ocean models predict that, with current rates of increase of $\mathrm{CO}_{2}$ in the atmosphere, and with ocean circulation and chemistry still only relatively slightly perturbed, the amount going into the ocean should presently be increasing (e.g. [14]). This is borne out by some observational studies, with, nevertheless, substantial uncertainty attached to them, based on attempts to quantify the rate of change of the ocean inventory of anthropogenic carbon [15]. However, in the future this may change owing to a number of feedback processes operating via the oceans. The possibilities identified so far mostly tend to decrease the sink, and are therefore positive feedbacks on climate. The two most important are likely to be the decreasing buffer capacity of the oceans due to increasing $\mathrm{CO}_{2}$ concentration in surface waters, and a reduction in the vertical circulation due to increasing surface ocean stratification. The first of these is an inevitable chemical consequence of rising $\mathrm{CO}_{2}$ - other things being equal, the amount of $\mathrm{CO}_{2}$ that must be added to sea water to equilibrate it with a given increase in atmospheric $\mathrm{CO}_{2}$ partial pressure decreases with each successive increment. The second effect would be a consequence of climate change that caused a warming and/or freshening of surface waters. This might reinforce the chemical buffering effect, by trapping water at the surface for a longer period, so that its $\mathrm{CO}_{2}$ concentration had more time to equilibrate with the atmosphere and therefore rose further. Alterations in the global circulation consequent on climate change will inevitably 
bring a wider array of influences on ocean uptake, with the likelihood of changes in the efficiency of the biological pump [16], the supply of nutrients such as phosphorus, nitrogen and iron, and the alkalinity of surface waters.

It would be desirable to better observe the ocean sink in order to have early warning of any such changes. While we are presently a long way from this goal, in a few locations in the world ocean, we have time series of surface measurements that are also spatially extensive, covering important parts of an ocean basin, which demonstrate how we might put in place an effective and useful observing system. These observations also show that the ocean-atmosphere flux over such ocean regions is very dynamic and coupled to indices of regional climate variability. We briefly describe these regional time series below.

\section{Direct observation of regional basin-scale changes}

\section{(a) Equatorial Pacific source, El Niño-Southern Oscillation and the Pacific Decadal Oscillation}

Since 1981, observations of the sea-surface $p \mathrm{CO}_{2}$ have been made in the equatorial Pacific by the National Oceanic and Atmospheric Administration (NOAA) during the biannual servicing of the Tropical Atmosphere Ocean experiment (TAO) array of buoys, which stretches from $5^{\circ} \mathrm{N}$ to $5^{\circ} \mathrm{S}$ and from $95^{\circ} \mathrm{W}$ to $130^{\circ} \mathrm{E}$, almost covering the whole width of the Pacific Ocean [17]. In addition to the TAO-related observations, the equatorial Pacific has been the focus of many oceanographic studies during the Joint Global Ocean Flux Study (JGOFS) era (e.g. [18]). This concentration of effort has led to an unparalleled dataset for sea-surface $p \mathrm{CO}_{2}$, from which air-sea fluxes can be calculated. The carbon observations in the region are found to correlate well with sea-surface temperature [19], allowing satellite temperature observations to be used to interpolate detail between the carbon observations.

The eastern and central equatorial Pacific is a large year-round source of carbon dioxide to the atmosphere, the outgassing being driven by the upwelling of waters from below the thermocline, due in turn to the equatorial divergence of surface currents [20]. In the western equatorial Pacific, the thermocline deepens and is frequently separated from the surface layer by a 'barrier layer' topped by a weak pycnocline, so that the upwelling water is not sourced from below the thermocline and is not high in $\mathrm{CO}_{2}$. The waters of this warm pool are close to equilibrium with the atmosphere. During El Niño conditions, the warm pool expands considerably and the thermocline deepens in the eastern Pacific, both leading to a reduction of the equatorial outgassing of $\mathrm{CO}_{2}$ to the atmosphere, so that there is a strong El Niño/La Niña signal in the resulting $\mathrm{CO}_{2}$ fluxes. Feely et al. [17] also identified a change in regime which they associated with the changing phase of the Pacific Decadal Oscillation (PDO), evident when comparing periods before 1986 and after 1990. Before this transition, the region seems to have been a slowly decreasing source of $\mathrm{CO}_{2}$ to the atmosphere, with the surface $p \mathrm{CO}_{2}$ changing little while atmospheric $\mathrm{CO}_{2}$ rose steadily. After this time, surface ocean $p \mathrm{CO}_{2}$ tends to increase in parallel with the atmospheric increase. Therefore, equatorial Pacific carbon data show the ocean-atmosphere fluxes responding to both El Niño-Southern Oscillation (ENSO) and PDO climate indices, with a particularly emphatic response to the El Niño/La Niña signal. 


\section{Increasing Southern Annular Mode index and flatlining of the Southern Ocean sink}

Models suggest that the Southern Ocean is the largest sink region for anthropogenic $\mathrm{CO}_{2}$. In the region dominated by circumpolar flow, there is a net drift of surface water to the north due to the wind-driven Ekman flux. To supply this flow, a proportion of the surface water must be recently upwelled, and therefore has not previously been exposed to the rising atmospheric $\mathrm{CO}_{2}$. While at the surface, it takes up a larger amount, or perhaps releases a smaller amount, of $\mathrm{CO}_{2}$ than it would have done pre-industrially (in either case, this qualifies as a flux of 'anthropogenic $\mathrm{CO}_{2}$ ' into the water). Much of the surface water is then subducted into the interior north of the polar front, after a year or less at the surface, most of it forming Antarctic Intermediate water, and it takes the atmospheric $\mathrm{CO}_{2}$ with it into the ocean interior. In the most southerly region, away from the circumpolar current, there is a net southward flow, which feeds bottom water formation over the continental shelves, and this process can also remove anthropogenic $\mathrm{CO}_{2}$ from the surface to the deepest ocean water.

As atmospheric $\mathrm{CO}_{2}$ continues to rise, most models suggest that this sink should be increasing, but Le Quéré et al. [21] used inversions of atmospheric measurements around the Southern Ocean to suggest that it has actually remained on average constant over the last two decades. During this period, wind speeds over the Southern Ocean have increased by nearly 20 per cent, a consequence of the more positive polarity of the Southern Annular Mode (SAM), which measures the strength of the pressure gradient between the sub-antarctic and mid-latitudes. Le Quéré et al. attribute this levelling out of the Southern Ocean $\mathrm{CO}_{2}$ sink to the increase in winds, leading to greater upwelling in the region, which increases the 'natural' (e.g. pre-industrial) outgassing associated with this upwelling [22]. They suggest that this effect counteracts the increased uptake, and that the net effect has been a roughly constant sink. (For the ocean as a whole, we might expect a net increase in uptake, as the net uptake is limited by ocean overturning and this has increased. Nevertheless, locally in the Southern Ocean the uptake remains level.)

Though for the Southern Ocean as a whole, we have very incomplete coverage of oceanic observations of $\mathrm{CO}_{2}$, in the Indian Ocean sector we do have a long time series, thanks to the French Oiso and Minerve programmes. These have used $p \mathrm{CO}_{2}$ observations made since 1991 on the regular voyages of the $\mathrm{R} / \mathrm{V}$ Marion Dufresne, the supply ship to the French Southern Territories, including Amsterdam, Crozet and Kerguelen islands. Figure 1 shows a compilation of these observations, which have recently been discussed in more detail by Metzl [23]. The apparently large scatter on the graph is not solely due to the innate variability of the ocean, but also reflects the fact that all seasons, and a great range of latitudes, are plotted here. The trend in the surface ocean $\mathrm{CO}_{2}$ is nevertheless well defined. It is rising faster than the atmospheric $\mathrm{CO}_{2}$, so that the ocean sink in this region might be expected to decrease on this account. On the other hand, the increase in wind speeds over the region will tend to drive an increase in the flux into the ocean: the overall effect is that the sink in this region has remained roughly constant over this nearly 20-year interval, in line with the treatment of Le Quéré et al. [21]. It is suggested that the causes of this flattening out of the Southern 


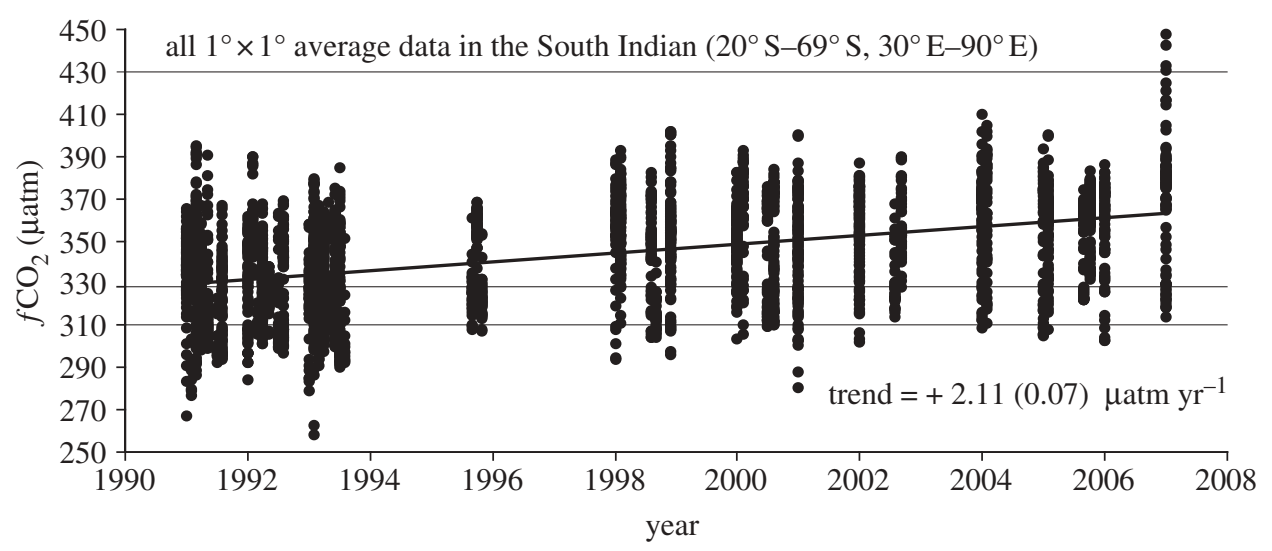

Figure 1. Compilation of data for surface ocean $p \mathrm{CO}_{2}$ for the period 1991-2007 from the Indian Ocean sector of the Southern Ocean. The overall trend line for all the data is shown, together with the slope of the trend line for the atmosphere during that time. Adapted from Metzl [23].

Ocean sink are Antarctic ozone depletion and increasing $\mathrm{CO}_{2}$ concentrations, which climate models predict are the main reasons for the strengthening of the polar vortex and thus the SAM in recent decades [24].

\section{The North Atlantic $\mathrm{CO}_{2}$ sink and the North Atlantic Oscillation}

The time series in the equatorial Pacific and the southern Indian Ocean have made use of the voyages of logistics supply vessels operating in comparatively remote oceans. In more travelled regions, a regular coverage of large ocean areas is possible by taking advantage of commercial vessels on major shipping routes. Commercial ships frequently sail over the same route approximately monthly, so that comparatively dense time series are possible. Typically, the ships are fitted with instrumentation that automatically measures sea-surface $p \mathrm{CO}_{2}$ and related variables using engine room intakes [25]; however, periodic manual sampling can deliver data of similar utility. In both the North Atlantic and Pacific, commercial ships have been used in this way since the early 1990s for $\mathrm{CO}_{2}$ observations. Long time series to date are in the Atlantic, on shipping routes between the UK and the Caribbean [25,26] and between Newfoundland and Iceland [27], where in each case data are available stretching back to the mid-1990s, though with substantial gaps before 2002 .

The North Atlantic is of great interest because it is an intense sink region for atmospheric $\mathrm{CO}_{2}$. The largest proportion of this flux is 'natural', e.g. it was occurring prior to the Industrial Revolution, and there is an additional component due to anthropogenic uptake. As water flows northward from the tropics in the Gulf Stream and its extension across the North Atlantic temperate zone, it cools and takes up carbon dioxide from the atmosphere. If water remains at the surface and recirculates, it eventually will give up the $\mathrm{CO}_{2}$ on returning southward. However, in the North Atlantic, a good fraction of the north-going water sinks and returns southward sub-surface, and by this process transports any atmospheric $\mathrm{CO}_{2}$ absorbed at the surface into the ocean interior. 


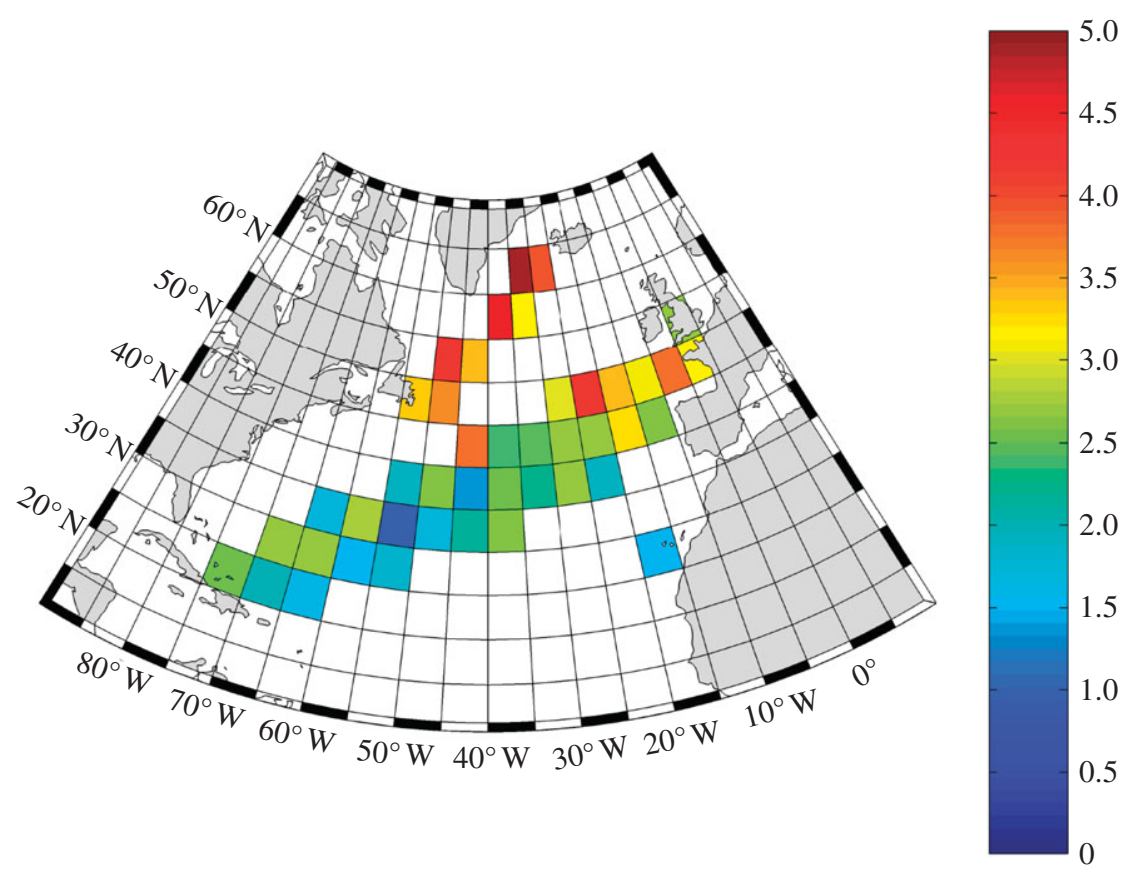

Figure 2. Trends in the rate of rise of surface water $p \mathrm{CO}_{2}\left(\right.$ in $\left.\mu a t m \mathrm{yr}^{-1}\right)$ in the North Atlantic, 1990-2006. Rates of increase were generally greater than the average atmospheric increase of $1.7 \mu \mathrm{atm} \mathrm{yr}^{-1}$ except for some squares in the south of the region. The trends were calculated by Schuster et al. [28] using a least-squares fit to the data in each $5 \times 5^{\circ}$ square, where there was sufficient data. The expression fitted was of the form $p \mathrm{CO}_{2}=a+b t+c \sin (\omega t+\phi)$, where $\omega$ is an angular frequency of $2 \pi \mathrm{yr}^{-1}$, and $a, b, c$ and $\phi$ were calculated by the least-squares procedure. The quantity plotted in the figure is then the linear increase term $b$.

On both of the UK-Caribbean and Iceland-Newfoundland routes, we observe that the flux into the water declined in strength between the mid-1990s and the early 2000s. Figure 2 [28] shows that, over most of the region, the rise in surface water $p \mathrm{CO}_{2}$ was more rapid than the atmospheric rise, with the trend being most pronounced towards the north of the region. The rates of rise were calculated as linear fits to the data available in the $5^{\circ} \times 5^{\circ}$ squares, after accounting for a sinusoidal seasonal cycle, and the figure also incorporates data from the European Station for Time Series in the Ocean (ESTOC: González-Dávila et al. [29]) and Bermuda Atlantic Time Series (BATS) [30] sites in the eastern and western subtropical North Atlantic.

It is probable that the decline in the uptake of $\mathrm{CO}_{2}$ by the northern North Atlantic over this time period is linked to change of the phase of the North Atlantic Oscillation (NAO), which is the dominant climate mode over this region $[26,28,31]$. The wintertime NAO was strongly positive for about a decade up to the mid-1990s, but subsequently, up to the early 2000s, was negative or neutral. A positive NAO corresponds to a more northerly track for winter cyclones in the North Atlantic, with the result that cooling and deep convection are favoured in the Labrador Sea, leading to substantial transformation of surface 
water into intermediate water. Copious formation of the Labrador Sea deep water occurred during the early 1990s, causing the subpolar gyre of the North Atlantic to expand and circulate more actively, taking up more atmospheric $\mathrm{CO}_{2}$. After 1995, deep convection in the Labrador Sea ceased, and the subpolar gyre shrank and span down over subsequent years.

However, the relationship of the NAO to $\mathrm{CO}_{2}$ uptake in the North Atlantic as a whole is not a simple cause and effect. Observations of the flux into the ocean over the UK-Caribbean route during the period 2002-2007 show a steady rise from a low point in 2002 to a peak in 2005, followed by a decline [32]. The NAO index does not show this pattern, and over this period has not shown a clear trend in the way it did in the decade of the 1990s; so it is probable that other climate trends have had more influence on the circulation of the North Atlantic during this period.

\section{An observational strategy for the ocean $\mathrm{CO}_{2}$ sink}

Between 2005 and 2008, as part of the CarboOcean project funded by the European Commission, a network, shown in figure 3, usually consisting of five or six 'voluntary observing ships' (VOS) plying regular routes in the North Atlantic, was in operation. These included the longer running commercial ship lines described above, with several more lines begun specifically for the project. To these sources of observations were added the fixed time series at ESTOC and BATS, and regular observations in the Caribbean made by NOAA [33]. A year of operations of this network has recently been reported [32]. The network enabled a detailed seasonal and spatial description of the pattern of air-sea flux over the entire North Atlantic region. Surface $\mathrm{CO}_{2}$ observations were correlated with re-analyses of sea-surface temperature and mixed layer depth to enable reconstruction of basin-wide fluxes.

During CarboOcean, perhaps a more significant result than the estimate of the flux into the North Atlantic was the analysis of the uncertainties inherent in the estimate based on this prototype network. Several different methods were applied to estimate the uncertainties inherent in the reconstructions. Because seasurface $\mathrm{CO}_{2}$ patterns are heterogeneous on all scales larger than a few kilometres, no single technique is unequivocally the best at determining the uncertainty, but both statistical methods applied to the $\mathrm{CO}_{2}$ data, and experiments in subsampling of a one-twelfth degree resolution model [34] were used to make these estimates. All the techniques, discussed in detail in the electronic supplementary material of the paper by Watson et al. [32], suggest that, for the basin-wide annually averaged flux into the North Atlantic, the network was able to define the sink with a $(1 \sigma)$ precision of 10 per cent or better. The precision of these studies in defining the annual average sink is therefore good, perhaps surprisingly so. This comes about because there are sufficient observations to provide a statistically representative subsample of conditions over the whole region, with no season or region that contributes greatly to the flux remaining unsampled. We are careful here to quote a precision, rather than absolute accuracy, because there may be a systematic error associated with the gas transfer velocity parametrization. For much of the last two decades it has been common to quote nearly a factor 


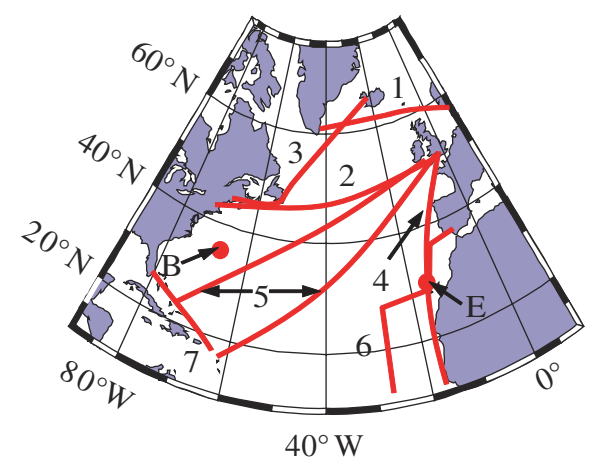

Figure 3. Location of the VOS routes and time-series stations that supplied surface ocean $\mathrm{CO}_{2}$ data to the CarboOcean network running through 2005. The network was found to be able to define the net air-sea flux over the region as a whole to a precision of order $10 \%$ (adapted from Watson et al. [32]).

of two uncertainty on this account, but recent advances have largely resolved these discrepancies, so the systematic error is unlikely now to be greater than 20 per cent $[33,35]$.

\section{Conclusion}

Ocean $\mathrm{CO}_{2}$ uptake varies with regional climate indices, as the observations we have reviewed here clearly show. This has some important consequences for our attempts to understand and predict future anthropogenic $\mathrm{CO}_{2}$ budgets. It confirms that ocean uptake is sensitive to climate change -something we would predict in any case from our present understanding of what controls the atmosphere-ocean flux. While the absolute amount of anthropogenic $\mathrm{CO}_{2}$ entering the oceans has been increasing modestly in recent decades, the fraction of anthropogenic emissions being taken up by the ocean appears to have been declining. For example, Sabine et al. [36] calculate that $42 \pm 7$ per cent of fossilfuel plus net biosphere emissions have been taken up by the oceans since the Industrial Revolution. However, the IPCC calculate that, between 1980 and 2005, ocean uptake accounted for only $37 \pm 7$ per cent [37]. Most predictions based on IPCC scenarios for future emissions suggest that this fraction will decline further in the coming century (e.g. [37, fig. 7.13]). The declining fraction going into the ocean occurs despite the fact that the absolute amount going into the ocean increases over this time period. It is due in part simply to an increasing $\mathrm{CO}_{2}$ emission rate but also due to the changes in ocean chemistry and stratification discussed above. Quantifying the ocean sink will be complicated by its short-term and regional variability, and our goal over the next few years should be to put in place a network of observations that is sufficient to track this variability. The experience in the North Atlantic shows that this is possible, at least for the Northern Hemisphere oceans and probably for the majority of the Southern Hemisphere as well. We have shown that in principle it is possible to quantify the ocean sink to within about 10 per cent on an annual and regional basis, and by doing so we can help to constrain the overall land 
vegetation sink to a considerable degree. Such an observing network is an essential component of a global observing system of carbon dioxide besides supporting physical, chemical and biological parameters. Many commercial vessels trade across ocean basins along regular routes, as e.g. in the North Atlantic, giving the opportunity to obtain repeated measurements to study temporal and spatial variability [38]. These observations are crucial if we are to know how the Earth system is responding to the disturbances to which we are subjecting it in the twenty-first century.

We thank the European Commission for support under the CarboOcean project (511176 GOCE), the Natural Environment Research Council in the UK, and INSU and l'Institut Paul Emile Victor in France for financial support. We thank the staff of Seatrade Reefers, Geest Line and the R/V Marion Dufresne for support and cooperation in obtaining observations at sea.

\section{References}

1 Bolin, B. \& Eriksson, E. 1959 Changes in the carbon dioxide content of the atmosphere and sea due to fossil fuel combustion. In The atmosphere and the sea in motion (ed. B. Bolin), pp. 130-142. New York, NY: Rockefeller Press.

2 Bolin, B. 1960 On the exchange of carbon dioxide between the atmosphere and the sea. Tellus 12, 274-281. (doi:10.1111/j.2153-3490.1960.tb01311.x)

3 Oeschger, H., Siegenthaler, U., Schotterer, U. \& Gugelmann, A. 1975 A box diffusion model to study the carbon dioxide exchange in nature. Tellus 27, 168-192. (doi:10.1111/j.2153-3490. 1975.tb01671.x)

4 Bolin, B., Keeling, C. D., Bacastrow, R. B., Björkström, A. \& Siegenthaler, U. 1981 Carbon cycle modelling. In SCOPE 16: carbon cycle modelling (ed. B. Bolin), pp. 1-31. New York, NY: John Wiley and Sons.

5 Le Quéré, C. et al. 2003 Two decades of ocean $\mathrm{CO}_{2}$ sink and variability. Tellus B 55, 649-656. (doi:10.1034/j.1600-0889.2003.00043.x)

6 Canadell, J. G. et al. 2007 Contributions to accelerating atmospheric $\mathrm{CO}_{2}$ growth from economic activity, carbon intensity, and efficiency of natural sinks. Proc. Natl Acad. Sci. USA 104, 18 866-18 870. (doi:10.1073/pnas.0702737104)

7 Gruber, N., Sarmiento, J. L. \& Stoker, T. F. 1996 An improved method for detecting anthropogenic $\mathrm{CO}_{2}$ in the oceans. Global Biogeochem. Cycles 10, 809-837. (doi:10.1029/ 96GB01608)

8 Friis, K. 2006 A review of marine anthropogenic $\mathrm{CO}_{2}$ definitions: introducing a thermodynamic approach based on observations. Tellus B 58, 2-15. (doi:10.1111/j.1600-0889.2005.00173.x)

9 Patra, P. K., Maksyutov, S., Ishizawa, M., Nakazawa, T., Takahashi, T. \& Ukita, J. 2005 Interannual and decadal changes in the sea-air $\mathrm{CO}_{2}$ flux from atmospheric $\mathrm{CO}_{2}$ inverse modeling. Global Biogeochem. Cycles 19, GB4013. (doi:10.1029/2004GB002257)

10 Gruber, N., Stendardo, I., Frohlicher, T. \& Johnson, G. C. 2009 The recent deoxygenation of the North Atlantic thermocline: a harbinger of the future? Geochim. Cosmochim. Acta $\mathbf{7 3}$ (Suppl.), A471.

11 Manning, A. C. \& Keeling, R. F. 2006 Global oceanic and land biotic carbon sinks from the Scripps atmospheric oxygen flask sampling network. Tellus B 58, 95-116. (doi:10.1111/ j.1600-0889.2006.00175.x)

12 Takahashi, T. et al. 2009 Climatological mean and decadal change in surface ocean $\mathrm{pCO}_{2}$, and net sea-air $\mathrm{CO}_{2}$ flux over the global oceans. Deep Sea Res. II Top. Stud. Oceanogr. 56, 554-577. (doi:10.1016/j.dsr2.2008.12.009)

13 Sarmiento, J. L. \& Sundquist, E. T. 1992 Revised budget for the oceanic uptake of anthropogenic carbon dioxide. Nature 356, 589-593. (doi:10.1038/356589a0)

14 Le Quéré, C. et al. 2009 Trends in the sources and sinks of carbon dioxide. Nat. Geosci. 2, 831-836. (doi:10.1038/ngeo689) 
15 Khatiwala, S., Primeau, F. \& Hall, T. 2009 Reconstruction of the history of anthropogenic $\mathrm{CO}_{2}$ concentrations in the ocean. Nature 462, 346-349. (doi:10.1038/nature08526)

16 Sarmiento, J. L. \& LeQuéré, C. 1996 Oceanic carbon dioxide uptake in a model of century-scale global warming. Science 274, 1346-1350. (doi:10.1126/science.274.5291.1346)

17 Feely, R. A., Takahashi, T., Wanninkhof, R., McPhaden, M. J., Cosca, C. E., Sutherland, S. C. \& Carr, M. E. 2006 Decadal variability of the air-sea $\mathrm{CO}_{2}$ fluxes in the equatorial Pacific Ocean. J. Geophys. Res. Oceans 111, C08S90. (doi:10.1029/2005JC003129)

18 Feely, R. A. et al. 2002 Seasonal and interannual variability of $\mathrm{CO}_{2}$ in the equatorial Pacific. Deep Sea Res. II Top. Stud. Oceanogr. 49, 2443-2469. (doi:10.1016/S0967-0645(02)00044-9)

19 Boutin, J. et al. 1999 Satellite sea surface temperature: a powerful tool for interpreting in situ $\mathrm{pCO}_{2}$ measurements in the equatorial Pacific Ocean. Tellus B 51, 490-508. (doi:10.1034/ j.1600-0889.1999.00025.x)

20 Ishii, M. et al. 2009 Spatial variability and decadal trend of the oceanic $\mathrm{CO}_{2}$ in the western equatorial Pacific warm/fresh water. Deep Sea Res. II Top. Stud. Oceanogr. 56, 591-606. (doi:10.1016/j.dsr2.2009.01.002)

21 Le Quéré, C. et al. 2007 Saturation of the Southern Ocean $\mathrm{CO}_{2}$ sink due to recent climate change. Science 316, 1735-1738. (doi:10.1126/science.1136188)

22 Watson, A. J. \& Garabato, A. C. N. 2006 The role of Southern Ocean mixing and upwelling in glacial-interglacial atmospheric $\mathrm{CO}_{2}$ change. Tellus B 58, 73-87. (doi:10.1111/ j.1600-0889.2005.00167.x)

23 Metzl, N. 2009 Decadal increase of oceanic carbon dioxide in Southern Indian Ocean surface waters (1991-2007). Deep Sea Res. II Top. Stud. Oceanogr. 56, 607-619. (doi:10.1016/j. dsr2.2008.12.007)

24 Lenton, A., Codron, F., Bopp, L., Metzl, N., Cadule, P., Tagliabue, A. \& Le Sommer, J. 2009 Stratospheric ozone depletion reduces ocean carbon uptake and enhances ocean acidification. Geophys. Res. Lett. 36, L12606. (doi:10.1029/2009GL038227)

25 Cooper, D. J., Watson, A. J. \& Ling, R. D. 1998 Variation of $p \mathrm{CO}_{2}$ along a North Atlantic shipping route (UK to the Caribbean): a year of automated observations. Mar. Chem. 60, 147-164. (doi:10.1016/S0304-4203(97)00082-0)

26 Schuster, U. \& Watson, A. J. 2007 A variable and decreasing sink for atmospheric $\mathrm{CO}_{2}$ in the North Atlantic. J. Geophys. Res. Oceans 112, C11006. (doi:10.1029/2006JC003941)

27 Corbiere, A., Metzl, N., Reverdin, G., Brunet, C. \& Takahashi, A. 2007 Interannual and decadal variability of the oceanic carbon sink in the North Atlantic subpolar gyre. Tellus B 59, 168-178. (doi:10.1111/j.1600-0889.2006.00232.x)

28 Schuster, U., Watson, A. J., Bates, N. R., Corbiere, A., González-Dávila, M., Metzl, N., Pierrot, D. \& Santana-Casiano, M. 2009 Trends in North Atlantic sea-surface $\mathrm{fCO}_{2}$ from 1990 to 2006. Deep Sea Res. II. Top. Stud. Oceanogr. 56, 620-629. (doi:10.1016/j.dsr2.2008.12.011)

29 González-Dávila, M., Santana-Casiano, J. M., Rueda, M. J., Llinás, O. \& González-Dávila, E. F. 2003 Seasonal and interannual variability of sea-surface carbon dioxide species at the European Station for Time Series in the Ocean at the Canary Islands (ESTOC) between 1996 and 2000. Global Biogeochem. Cycles 17, 1076. (doi:10.1029/2002GB001993)

30 Bates, N. R. 2007 Interannual variability of the oceanic $\mathrm{CO}_{2}$ sink in the subtropical gyre of the North Atlantic Ocean over the last 2 decades. J. Geophys. Res. Oceans 112, C09013. (doi:10.1029/2006JC003759)

31 Thomas, H., Prowe, A. E. F., Lima, I. D., Doney, S. C., Wanninkhof, R., Greatbatch, R. J., Schuster, U. \& Corbiere, A. 2008 Changes in the North Atlantic Oscillation influence $\mathrm{CO}_{2}$ uptake in the North Atlantic over the past 2 decades. Global Biogeochem. Cycles 22, GB4027. (doi:10.1029/2007GB003167)

32 Watson, A. J. et al. 2009 Tracking the variable North Atlantic sink for atmospheric $\mathrm{CO}_{2}$. Science 326, 1391-1393. (doi:10.1126/science.1177394)

33 Sweeney, C., Gloor, E., Jacobson, A. R., Key, R. M., McKinley, G., Sarmiento, J. L. \& Wanninkhof, R. 2007 Constraining global air-sea gas exchange for $\mathrm{CO}_{2}$ with recent bomb ${ }^{14}$ C measurements. Global Biogeochem. Cycles 21, GB2015. (doi:10.1029/2006GB002784)

34 Eden, C. \& Oschlies, A. 2006 Adiabatic reduction of circulation-related $\mathrm{CO}_{2}$ air-sea flux biases in a North Atlantic carbon-cycle model. Global Biogeochem. Cycles 20, GB2008. (doi:10.1029/2005GB002521) 
35 Muller, S. A., Joos, F., Plattner, G. K., Edwards, N. R. \& Stocker, T. F. 2008 Modeled natural and excess radiocarbon: sensitivities to the gas exchange formulation and ocean transport strength. Global Biogeochem. Cycles 22, GB3011. (doi:10.1029/2007GB003065)

36 Sabine, C. L., Feely, R. A., Johnson, G. C., Strutton, P. G., Lamb, M. F. \& McTaggart, K. E. 2004 A mixed layer carbon budget for the GasEx-2001 experiment. J. Geophys. Res. Oceans 109, C08S05. (doi:10.1029/2002JC001747)

37 IPCC 2007 Climate change 200\%: the physical science basis. Contribution of Working Group 1 to the Fourth Assessment Report of the IPCC (eds S. Solomon, D. Qin, M. Manning, Z. Chen, M. Marquis, K. B. Averyt, M. Tignor \& H. L. Miller). Cambridge, UK: Cambridge University Press.

38 Monteiro, P. M. S. et al. 2009 A global sea surface carbon observing system: assessment of changing sea surface $\mathrm{CO}_{2}$ and air-sea $\mathrm{CO}_{2}$ fluxes. In Proc. OceanObs'09, Venice, Italy, 21-25 September 2009 (eds J. Hall, D. E. Harrison \& D. Stammer). Community White Paper. ESA Special Publication. 